\title{
Corrosion Control of Alloy 690 by Shot Peening and Electropolishing under Simulated Primary Water Condition of PWRs
}

\author{
Kyung Mo Kim, Hee-Sang Shim, Myung Ji Seo, and Do Haeng Hur \\ Korea Atomic Energy Research Institute, 989-111 Daedeok-daero, Yuseong-gu, Daejeon 305-353, Republic of Korea \\ Correspondence should be addressed to Kyung Mo Kim; kmkim@kaeri.re.kr
}

Received 3 June 2015; Accepted 20 August 2015

Academic Editor: Randhir Singh

Copyright (C) 2015 Kyung Mo Kim et al. This is an open access article distributed under the Creative Commons Attribution License, which permits unrestricted use, distribution, and reproduction in any medium, provided the original work is properly cited.

\begin{abstract}
This work clarifies the effect of surface modifications on the corrosion rate of Alloy 690, a nickel-based alloy for steam generator tubes, under the simulated test conditions of the primary water chemistry in nuclear power plants. The surface stress was modified by the shot peening and electropolishing methods. The shot peening treatment was applied using ceramic beads with different intensities by varying the air pressure and projection angle. The corrosion rate was evaluated by gravimetric analysis and the surface was analyzed by scanning electron microscopy (SEM). The corrosion rate of Alloy 690 was evaluated from the influence of the stress state on the metal surface. Based on the observation of the surface after the corrosion test, the oxide composition and its structure were affected by the surface modifications. The corrosion behavior of Alloy 690 was distinguished by the shot peening intensity on the surface, and additional electropolishing was effective at reducing the dissolution of nickel ions from the metal surface.
\end{abstract}

\section{Introduction}

The dissolution control of nickel from steam generator (SG) tubes is important to reduce the radioactive dose rate and deterioration of fuel performance in the operation of pressurized water reactors (PWRs). The major sources of the radiation field in the primary coolant circuit including the reactor are known to be neutron reactions with nickel and cobalt ions in water. Corrosion products released from metal surface in the coolant circuit can be deposited on the reactor core forming the crud on the fuel surface during operation of power plant. The corrosion products prevent heat transfer from the fuel to the coolant and induce the growth of crud on the fuel cladding. The composition of the fuel crud consists mainly of nickel ferrite, which indicates that its primary source is the nickel contained in the SG tube materials $[1,2]$. Higher crud buildup might cause an increase in the axial offset anomalies through the corrosion products deposited on the surface of the fuel cladding [35]. To avoid problems originating from crud buildup, the primary water chemistry has been improved by various means, such as loading of hydrogen overpressure, reduction of the electrochemical potential, coordinated adjustment of the boron and lithium concentration, and zinc addition [38]. Zinc addition in operating PWR plants shows reducing radiation dose rates [3]. It is recommended on primary chemistry control to reduce the corrosion products for PWR type plants with plant-specific optimization. These alleviation methods need an exact evaluation of chemical conditions in primary coolant and effects on component integrity [4].

The corrosion properties are affected by the material's surface states including roughness, residual stress, and work hardening under the conditions of the reactor water chemistry [9]. The Alloy 600 SG tube material has been replaced with Alloy 690, which is resistant to stress corrosion cracking. However, the metal cations released from the surface might be accumulated in the primary circuit over long operation times, and other unknown manufacturing processes may affect the integrity of the Alloy 690 surface [2]. Clauzel et al. observed the corrosion behavior of Alloy 690 manufactured from various suppliers and classified the tubes according to their metallurgical properties, release, and corrosion 
TABLE 1: Chemical composition of Alloy 690.

\begin{tabular}{lcccccccc}
\hline $\mathrm{C}$ & $\mathrm{Cr}$ & $\mathrm{Fe}$ & $\mathrm{Ni}$ & $\mathrm{Si}$ & $\mathrm{Mn}$ & $\mathrm{Ti}$ & $\mathrm{Al}$ & $\mathrm{S}$ \\
\hline 0.015 & 28.2 & 9.5 & Bal. & 0.1 & 0.26 & 0.21 & 0.04 & $<0.002$ \\
\hline
\end{tabular}

properties in relation to microstructure, surface impurities, microhardness, roughness, and carbon content [10]. Guinard et al. [11] and Huang et al. [12] have studied the impact of different surface-state conditions, as well as the cold working, and electropolishing of Alloy 690 on its corrosion-release rate.

There are many studies on the metal-surface improvement using electropolishing and shot peening. The corrosion rate of electropolished stainless steel was lowered by more than a factor of three relative to that of machined surfaces in mild alkaline, hydrogenated water at $260^{\circ} \mathrm{C}$, and this reduction was explained by the decrease in surface microstrain [13]. It is known that the higher equilibrium concentration of $\mathrm{Cr}$ in Alloy 690 results in good resistance against failure induced by intergranular attack (IGA) and stress corrosion cracking (SCC) in high-temperature water environments [14]. Zhang et al. reported that the SCC of Alloy 690 was reduced by shot peening and electropolishing treatments [9]. Some studies also showed that compressive residual stresses inhibit the initiation of SCC $[15,16]$. However, the effects of the surface states on the corrosion and metal-ion dissolution properties of Alloy 690 have not been clearly evaluated, and the combined application of shot peening and electropolishing treatments on SG tubes needs to be experimentally studied.

The aim of this work is to study the reduction in the dissolution of metal ions from the Alloy 690 surface through surface modification in the simulated water chemistry of the primary system of PWRs. In this work, the applicability of shot peening and electropolishing on SG tube material was investigated, and the effect of these surface treatments on the corrosion-release behavior was evaluated.

\section{Experimental}

2.1. Material Preparation. The corrosion experiments were performed on Alloy 690 which was manufactured by POSCO Specialty Steel with the chemical composition listed in Table 1. The specimens were heat processed in two steps, namely, mill annealing (MA) and thermal treatment (TT), after being cold-rolled to the thickness of about $1.5 \mathrm{~mm}$. The samples were mill annealed at $1100^{\circ} \mathrm{C}$ for $5 \mathrm{~min}$, followed by water quenching, and then thermally treated at $715^{\circ} \mathrm{C}$ for $10 \mathrm{~h}$ in a vacuum furnace under the pressure of about $5 \times 10^{-6}$ Torr. The specimens were manufactured in plate shape with size of $45 \mathrm{~mm}$ in length and $15 \mathrm{~mm}$ in width. All the specimens have a hole of $3 \mathrm{~mm}$ in diameter in order to hang on a tree in the autoclave for high-temperature corrosion test.

2.2. Surface Treatment. Shot peening was performed on the flat specimens using ceramic beads $(0.125 \sim 0.250 \mathrm{~mm}$ in size). The shot peening process was conducted using a pressure-type blast machine (MPTB-01 model) manufactured by Korea Shot Blast Co., and the maximum air pressure for the shot peening instrument was 5 bars. The intensity and coverage during the shot peening process were measured using N-type Almen strips. Almen strips are flat metal strips that were exposed to shot peening under the same conditions as the specimens. Residual surface compressive stresses will make the strip bow upward in the middle when released. The height of this convexly bowed arc is an index of the intensity of the shot peening and was measured using a TSP-3 Almen gauge (Electronics Inc., USA). The surface microstrain was determined from high-resolution X-ray diffraction (HRXRD) measurements. For the residual stress evaluation of Alloy 690, Young's modulus of $211 \mathrm{GPa}$ and Poisson's ratio of 0.289 were used.

Table 2 lists the surface-processing procedures applied for shot peening and electropolishing of the specimens. The first test was performed to investigate the effect of only varying the air pressure used for shot peening on the corrosion behavior (specimens B-D).

Further shot peening processes were conducted at different angles and distances from the nozzle of the shot peening machine, namely, at $30^{\circ}$ and $75 \mathrm{~mm}$ (SP30), $45^{\circ}$ and $100 \mathrm{~mm}$ (SP45), and $90^{\circ}$ and $150 \mathrm{~mm}$ (SP90). In this test series, the shot peening air pressure was maintained at 1 bar for all specimens. After the shot peening treatment, the SP45 and SP90 specimens were further electropolished to improve the roughness of the shot-peened surfaces, marked as EP45 and EP90 specimens.

The electropolishing process was applied using the instrument type ElectoMet 4 (Buehler Co., IL). The electrolyte for electropolishing was a mixture of $70 \%$ phosphoric acid $\left(\mathrm{H}_{3} \mathrm{PO}_{4}\right), 15 \%$ sulfuric acid $\left(\mathrm{H}_{2} \mathrm{SO}_{4}\right)$, and $15 \%$ methanol $\left(\mathrm{CH}_{3} \mathrm{OH}\right)$. Electropolishing was conducted at $10 \mathrm{~V}$ and 1.6 to $1.7 \mathrm{~A}$, thereby maintaining the electrolyte temperature of $40^{\circ} \mathrm{C}$ and $50 \mathrm{cc} / \mathrm{min}$ circulation speed for about $1.5 \mathrm{~min}$. The surface morphology and roughness were investigated by scanning electron microscopy (SEM, JEOL JSM-5400 model) and the surface microhardness was measured using a Vickers hardness tester equipped with a pyramidal diamond indenter. The loading condition was $25 \mathrm{~g}$ for $10 \mathrm{~s}$.

2.3. Corrosion Test and Oxide Analysis. A recirculation loop with Hastelloy autoclave system was used during the long corrosion tests. The test environment simulated the primary water chemistry in a PWR. Dissolved oxygen (DO), dissolved hydrogen $(\mathrm{DH}), \mathrm{pH}$, and conductivity were monitored at room temperature using sensors manufactured by Orbisphere and Mettler Toledo. The temperature and pressure were maintained at $330^{\circ} \mathrm{C}$ and 150 bars, respectively, during the corrosion tests. The composition of the test solution was lithium ( $\mathrm{LiOH}, 2 \mathrm{ppm})$, boron $\left(\mathrm{H}_{3} \mathrm{BO}_{4}, 1,200 \mathrm{ppm}\right), \mathrm{DH}$ $(35 \mathrm{cc} / \mathrm{kg})$, and less than $5 \mathrm{ppb}$ of DO. The flow rate of the loop system was $3.8 \mathrm{~L} / \mathrm{h}$, and the corrosion tests were conducted for $500 \mathrm{~h}$.

The corrosion rate was evaluated by gravimetric analysis using an alkaline permanganate ammonium citrate (AP/AC) descaling process: $1 \% \mathrm{KMnO}_{4}$ and $5 \% \mathrm{NaOH}$ were exposed to the inner tube surface at $90^{\circ} \mathrm{C}$ for $3 \mathrm{~min}$ [17-19]. This 
TABLE 2: Conditions of the specimen's surface treatments.

\begin{tabular}{|c|c|c|c|c|c|}
\hline \multirow{2}{*}{ Specimen ID } & \multicolumn{4}{|c|}{ Shot peening } & \multirow{2}{*}{ Electropolishing } \\
\hline & Air pressure (bar) & Distance $(\mathrm{mm})$ & Angle $\left({ }^{\circ}\right)$ & Time (sec) & \\
\hline A & - & - & - & - & - \\
\hline B & 0.5 & 50 & 90 & 60 & - \\
\hline $\mathrm{C}$ & 1 & 50 & 90 & 60 & - \\
\hline $\mathrm{D}$ & 2 & 50 & 90 & 30 & - \\
\hline SP30 & 1 & 75 & 30 & 300 & - \\
\hline SP45 & 1 & 100 & 45 & 300 & - \\
\hline SP90 & 1 & 150 & 90 & 300 & - \\
\hline EP45 & 1 & 100 & 45 & 300 & Yes \\
\hline EP90 & 1 & 150 & 90 & 300 & Yes \\
\hline
\end{tabular}

method involves multiple applications and enables reverse extrapolation to correct for base-metal losses during the removal of the corrosion oxides.

The morphology and chemical composition of the surface oxide layers were analyzed using SEM and X-ray photoelectron spectroscopy (XPS). The XPS analysis was carried out using a spectrometer model Thermo Fisher Scientific (Theta Probe AR-XPS) XPS, equipped with $\mathrm{Al} \mathrm{K \alpha}$ X-ray source $(1486.6 \mathrm{eV})$ and operated at $15 \mathrm{kV}$ and $150 \mathrm{~W}$. The depth profiling was conducted in intervals of $60 \mathrm{~s}$ through Ar sputtering at the energy of $2 \mathrm{keV}$ and at the spot size of $400 \mu \mathrm{m}$.

\section{Results and Discussion}

3.1. Surface Stress State. The shot peening intensity was measured in dependence on the applied air pressure, as shown in Figure 1. The shot-peened surface shows saturation of its intensity value as the exposure time is held constant. The saturation time for a given test piece may be defined as the time necessary to attain a deflection such that, by doubling the treatment time, the deflection does not increase by more than $10 \%$. The arc deflection at saturation defines the peening intensity. The shot peening intensity was measured to be $10.1 \mathrm{~N}$ at an air pressure of 2 bars and a shot peening time of $30 \mathrm{~s}$. When the air pressure was reduced to 1 bar and 0.5 bars, the intensities decreased to $7.36 \mathrm{~N}$ and $5.51 \mathrm{~N}$, respectively, for a shot peening time of $60 \mathrm{~s}$. After these shot peening times, the intensity values showed no further increase.

The XRD patterns of the oxide layers are obtained to determine the crystal faces as a measure of the residual stress. The XRD patterns of the specimens shown in Figure 2 indicate that the shot peening treatment did not change the crystal structure of Alloy 690. The residual stress induced by shot peening on the surface was measured by an HRXRD instrument, and the results are shown in Figure 3. The residual stress was measured employing the Ni crystal faces of (111) and (311) at the surface of the specimens. The two stress levels are different but show a similar pattern in dependence on the air pressure applied during the shot peening. The results indicate that specimen $\mathrm{D}$ shot-peened at an air pressure of 2 bars shows lower residual stress than specimen B surface treated at an air pressure of 0.5 bars,

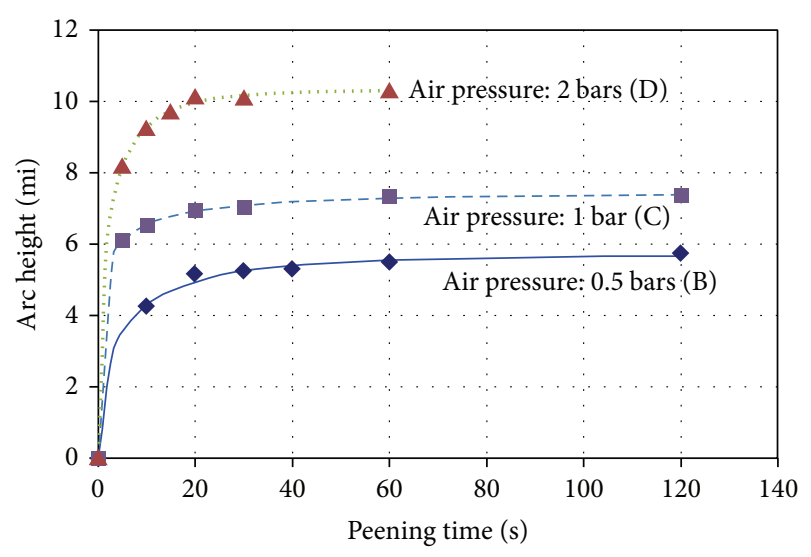

FIGURE 1: Shot peening intensity at different air pressure conditions.

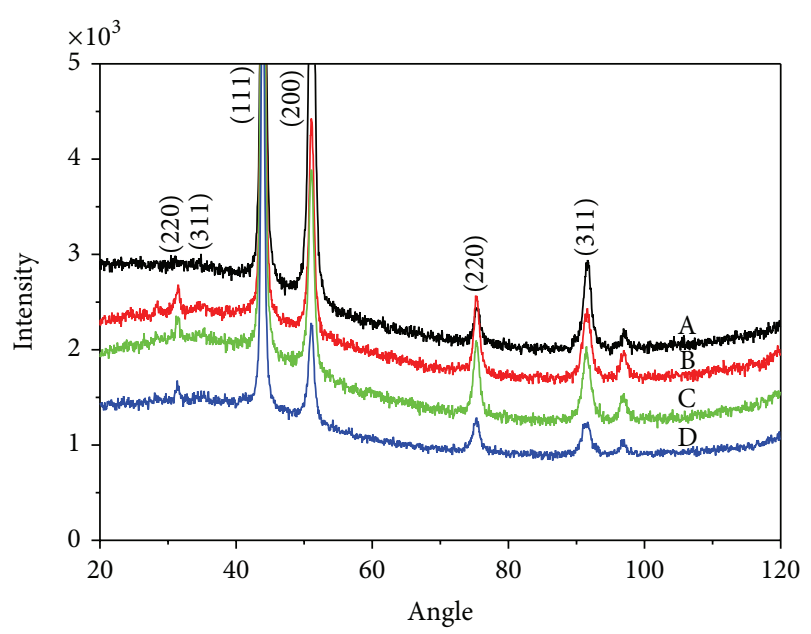

FIGURE 2: X-ray diffraction patterns of Alloy 690 at different shot peening intensity.

contrary to expectations, and it is considered with the change of surface morphology as explained with the next figures (Figures 4 and 5). In Figure 3, the Vickers microhardness indentations are depicted along with the residual stress values. The microhardness was measured at the distance of $20 \mu \mathrm{m}$ from the shot-peened surface. The hardness increases 


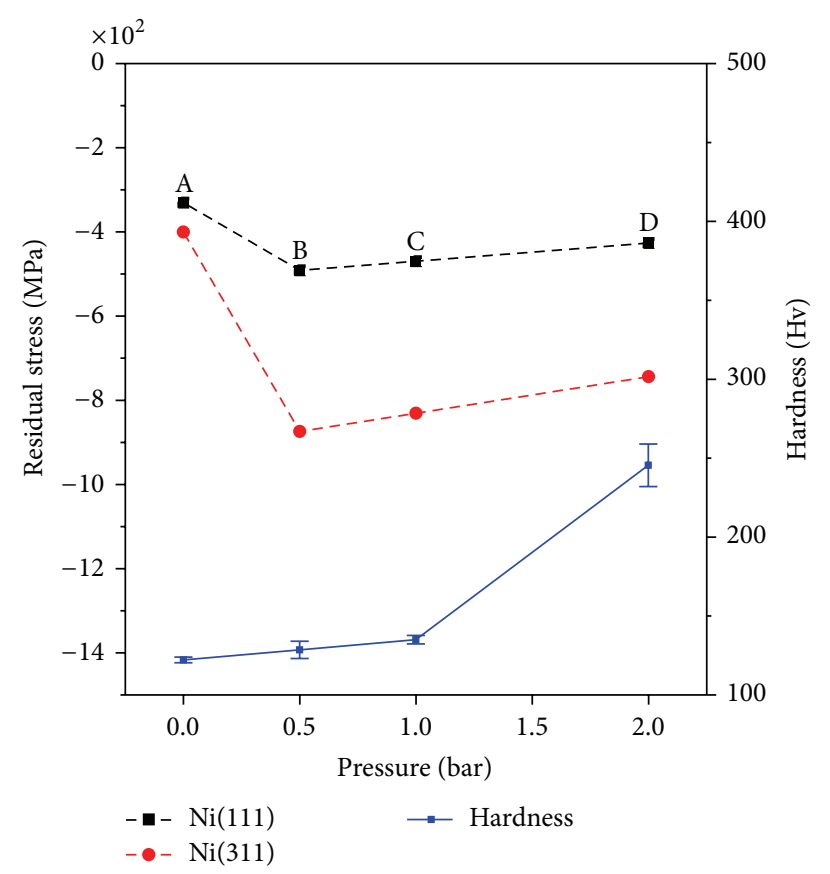

FIGURE 3: Residual stress and microhardness at different shot peening air pressure.

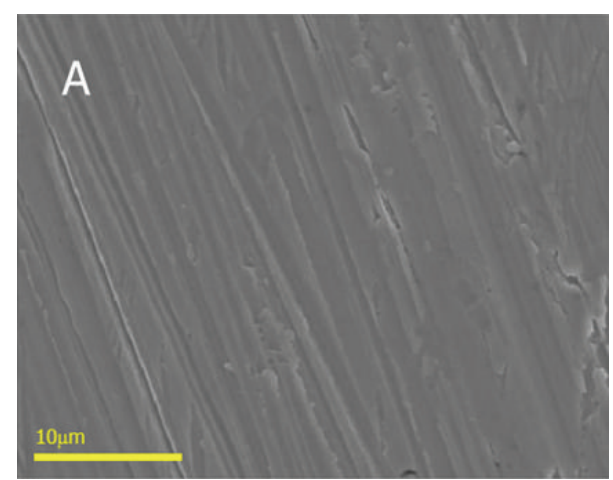

(a)

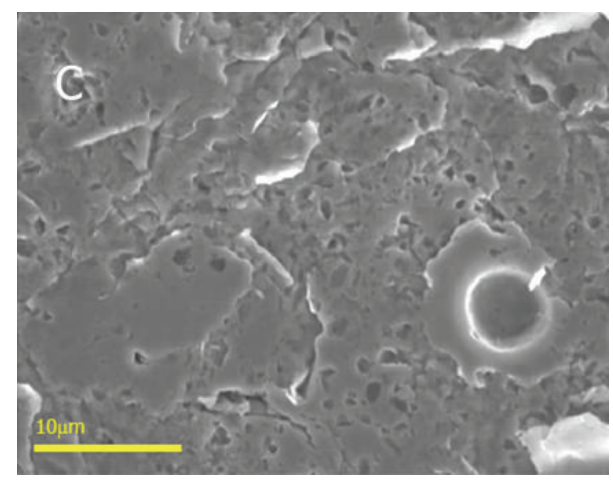

(c)

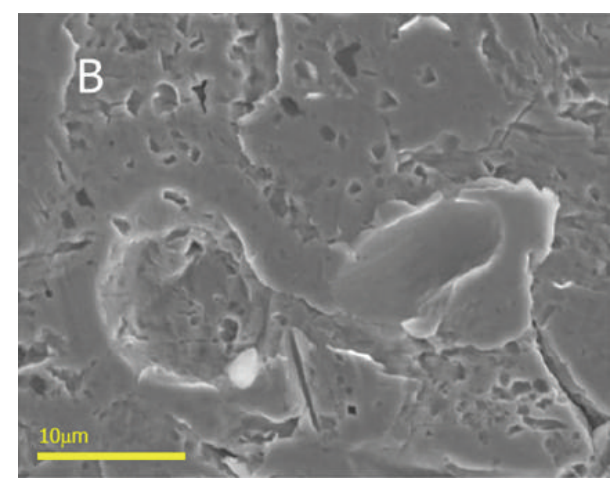

(b)

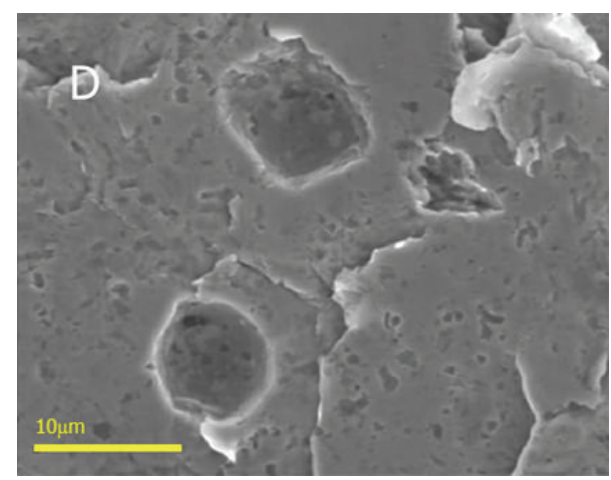

(d)

FIGURE 4: SEM photographs of the surface of shot-peened specimens at different air pressure. 


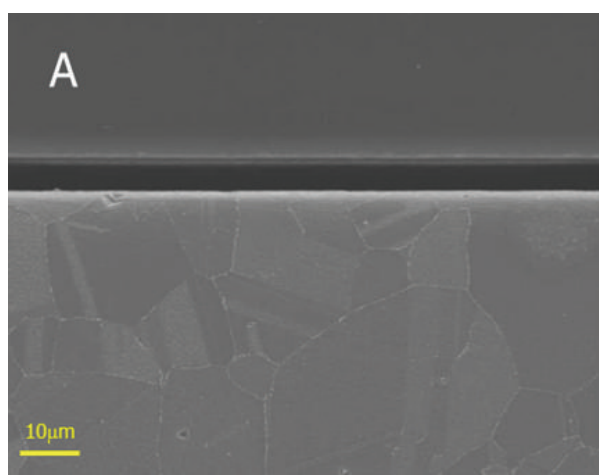

(a)

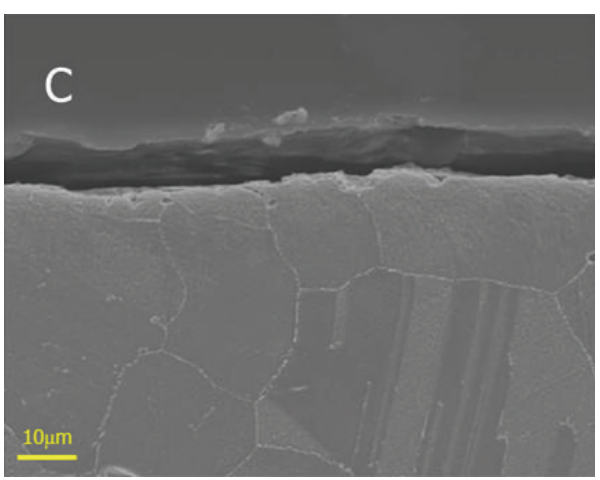

(c)

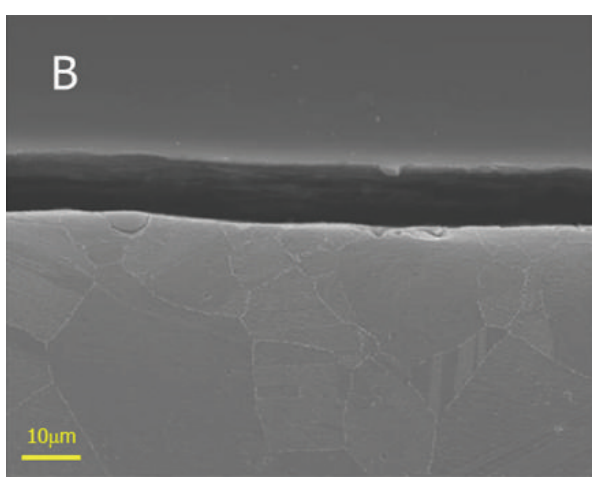

(b)

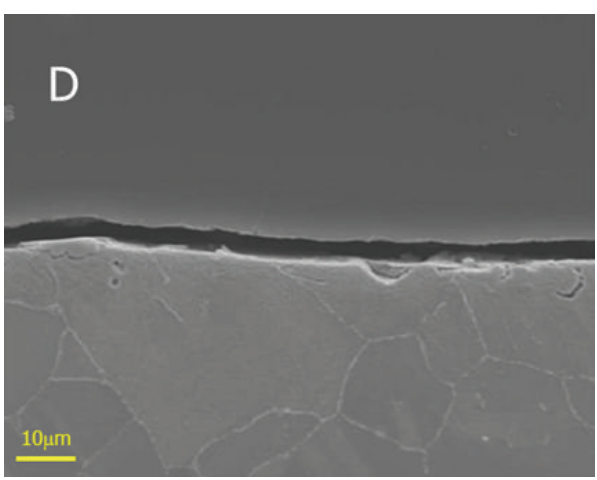

(d)

FIGURE 5: SEM photographs of the depth profile of the surface layer of shot-peened specimens at different air pressure.

with the shot peening intensity, and specimen D accordingly shows the hardest state.

The surface morphology of the specimens was observed by SEM and is shown in Figure 4 . Scratches are observed at the surface of specimen A, but the shot peening treatment removes them, as shown in Figures $4(\mathrm{~b})-4(\mathrm{~d})$. The shot peening causes circular indentations and imprints of the shot peening beads at the surface are more clearly formed at increasing shot peening intensity. The surface layer of the alloy was slightly smeared and/or redistributed by the shot peening. No particle embedment is observed and the occurrence of bead contamination is not considered. The depth profile (Figure 5) shows the breakaway of some small parts at the outer surface at high shot peening intensity. The decrease of the residual stress at higher shot peening intensities of specimen D, as shown in Figure 3, can be explained as the stress relief induced from microcracking by excessive shot peening intensity over metal fracture stress.

High intensity of the shot peening (higher than about $7 \mathrm{~N}$ ) might cause problems such as crack initiation. To improve the surface integrity, the intensities were lowered by changing the incident angle and the distance from the peening nozzle. The shot peening intensity is determined to be about 4.5$6 \mathrm{~N}$ based on the Almen-strip measurements, as shown in Figure 6. The intensity difference between samples SP30 and SP45 was affected more by the incidence angle than by the distance. On the other hand, the intensity value of the

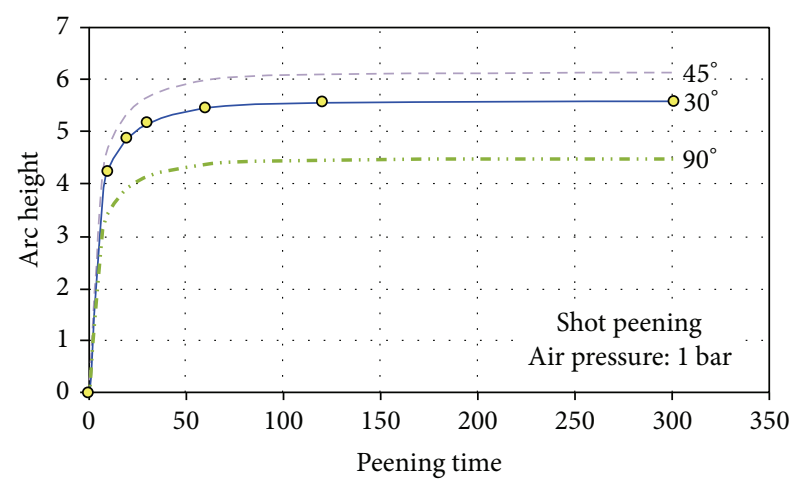

Figure 6: Almen-strip saturation curves at different shot peening incidence angles.

SP90 sample shows higher variation in dependence on the distance than on the angle. Figure 7 shows the values of the residual stress and microhardness. The changes induced by electropolishing after the shot peening were not large compared with the values already obtained by applying only shot peening.

The surface morphologies of all specimens are shown in Figure 8 . The surfaces processed by shot peening (Figures $8(\mathrm{~b})-8(\mathrm{~d}))$ show a slightly larger number of dimples and a scaled appearance, similar to Figure 4, but these structures 


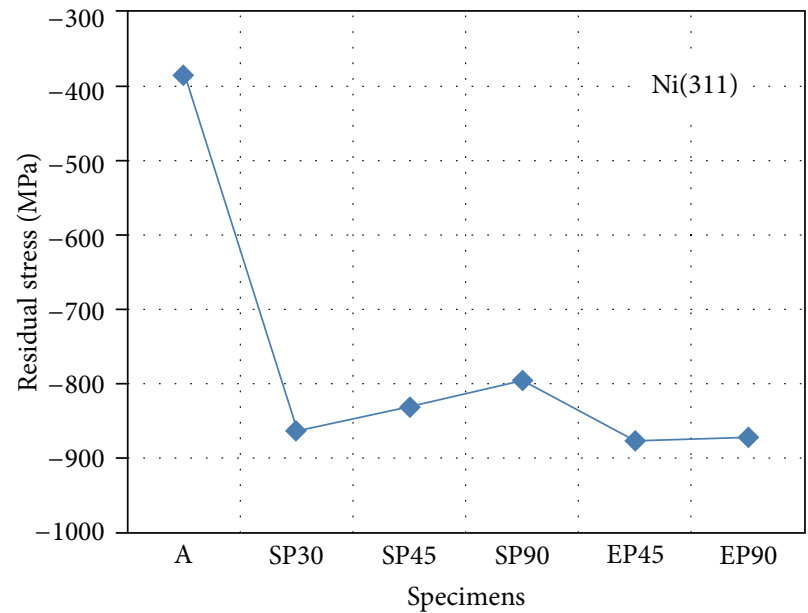

(a)

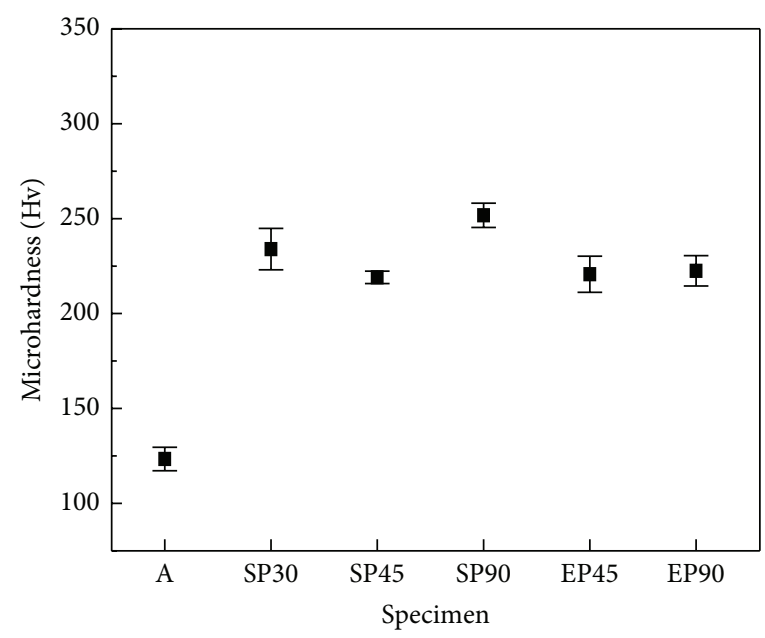

(b)

FIGURE 7: (a) Residual surface stress measured by XRD and (b) microhardness measured at the depth of $20 \mu \mathrm{m}$ from the surface of shotpeened and electropolished specimens. The specimen labels distinguish the different surface treatments: shot peening at 1 bar with angles of $30^{\circ}$ (SP30), $45^{\circ}$ (SP45), and $90^{\circ}$ (SP90) and electropolishing after shot peening with angles of $45^{\circ}$ (EP45) and 90 (EP90).

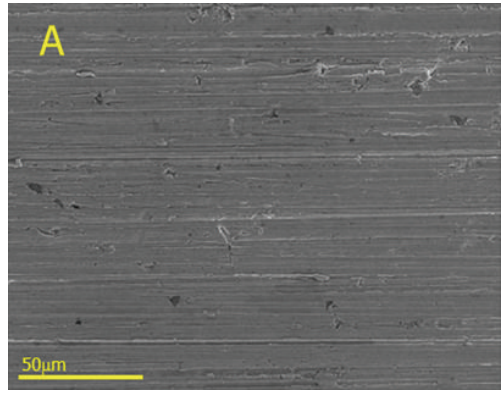

(a)

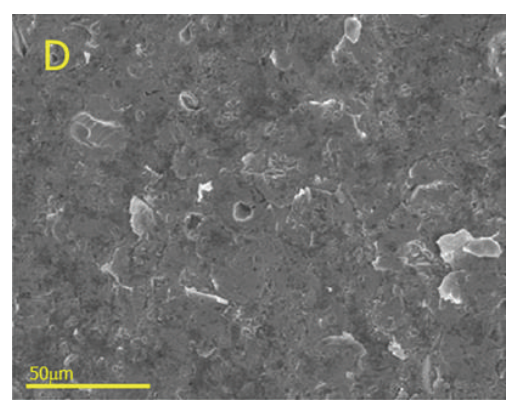

(d)

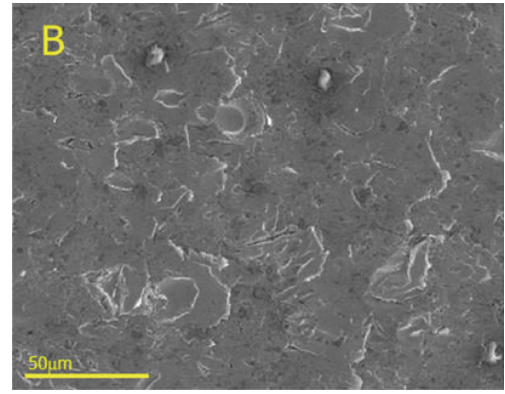

(b)

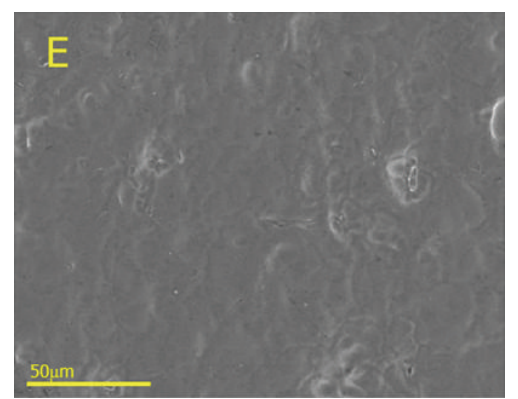

(e)

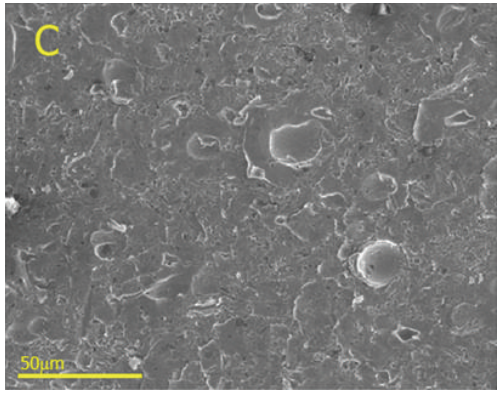

(c)

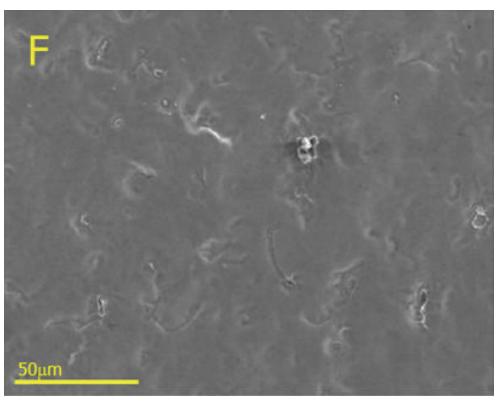

(f)

FIGURE 8: SEM photographs of the surface before the corrosion tests for specimens of (a) reference, (b) SP30, (c) SP45, (d) SP90, (e) EP45, and (f) EP90.

are formed to a lesser degree than in case of high shot peening intensity. The samples being subject to the electropolishing treatment show blunt dimples induced by the shot peening but an overall smoother surface achieved by electropolishing in comparison to the samples processed only by shot peening (Figures $8(\mathrm{e})-8(\mathrm{f})$ ). It is known that deformation twinning and the number of dislocations increase upon increasing the peening intensity, which was inferred from TEM observations of the surface of nickel-based alloys [20].
3.2. Corrosion Behavior Modified by Surface Treatments. Immersion tests were performed using specimens processed by shot peening at different intensities with or without electropolishing treatment in primary water chemistry environment, and the corrosion rates were measured, as shown in Figure 9. The corrosion rate at different air pressures of the shot peening was measured to be $1.45 \mathrm{mg} / \mathrm{m}^{2} \mathrm{~h}$ for asreceived specimen A (Figure 9(a)). The corrosion rates of the specimens treated at different shot peening intensities are 


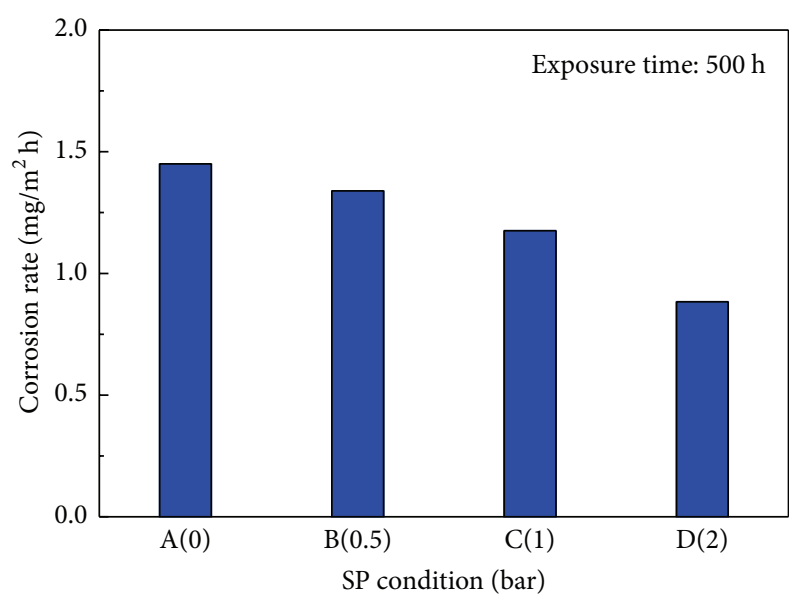

(a)

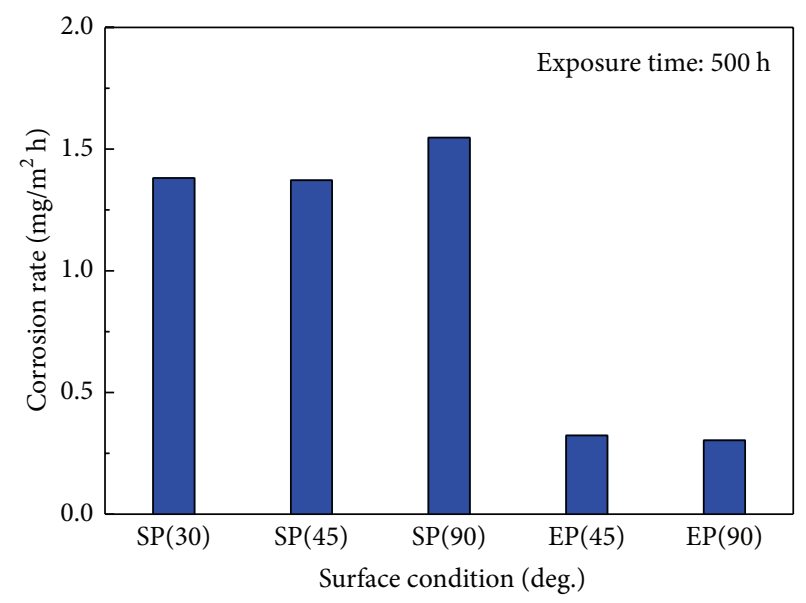

(b)

FIGURE 9: Corrosion rates of Alloy 690 processed with different surface treatments: variation of the shot peening air pressure (a) and incidence angle (b).

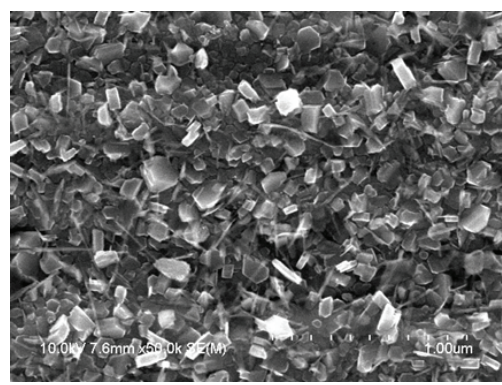

(a)

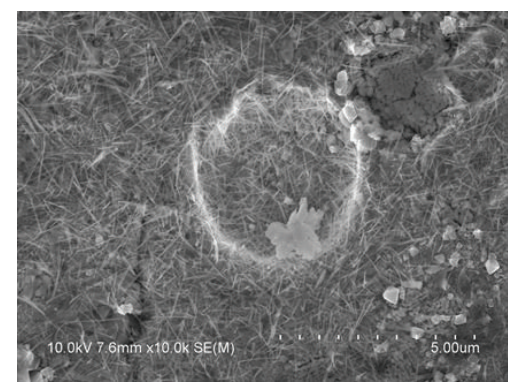

(b)

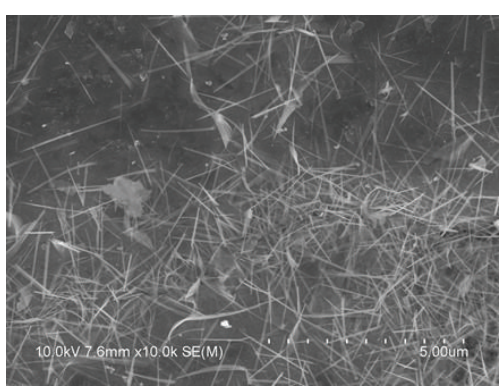

(c)

FIGURE 10: SEM photographs after corrosion test of $500 \mathrm{~h}$ for specimens of different surface treatments: (a) reference specimen, (b) specimen SP45, shot peening only, and (c) specimen EP45, electropolishing after shot peening.

shown to have the values of $1.34,1.18$, and $0.88 \mathrm{mg} / \mathrm{m}^{2} \mathrm{~h}$ for specimens B, C, and D, respectively. Specimen D treated at high shot peening intensity shows a decrease of about $40 \%$ in the corrosion rate in comparison to as-received specimen A. Figure 9(b) shows the corrosion test results for the samples processed at different shot peening angles and distances, with or without electropolishing. The results indicate that weak shot peening was not effective for the reduction of the dissolution rate of metal ions (SP30, SP45, and SP90 specimens), whereas electropolishing after the shot peening (EP45, EP90 specimens) decreased the corrosion rate to less than $1 / 4$ of that of reference specimen $A$.

The observations of the oxidic surface are shown in Figure 10. The oxide layer formed on reference specimen A shows a polyhedral crystal structure (Figure 10(a)), but the oxide layer on the shot-peened surface shows an almost needlelike morphology with small additional platelike particles (Figure 10(b)). In the case of electropolished surfaces, the needlelike oxides were concentrated in the dimples induced by shot peening whereas the outer surface showed little coverage of deposited oxides (Figure 10(c)). Investigation of
Seo et al. about the corrosion behavior of Alloy 690 at hightemperature condition shows that the change of the oxide morphology from polyhedral to wirelike shape was induced by a roughness change of the surface [21].

The increase in roughness by shot peening might be assumed to have a negative effect on the corrosion behavior; however, the results of the corrosion tests in primary environment indicate that the corrosion rate was reduced on increasing shot peening intensity. The depth of the oxide film might grow by the chemical reaction and deposition of metal ions in solution or by a metallic transfer from the metaloxide interface. Because the corrosion environment was not changed, the different test results show that the corrosion rate relies on the metal-ion dissolution rate at the metaloxide interface, and the metal-ion transfer depends on the residual stress in the metallic surface layer. The compressive residual stress formed in the sublayer beneath the outer metal surface of the specimen is considered to constrain the metalion release into the oxide film or solution [9]. The corrosion rate is proportional to the concentration gradient of the metallic species near the metal-oxide interface and to the 


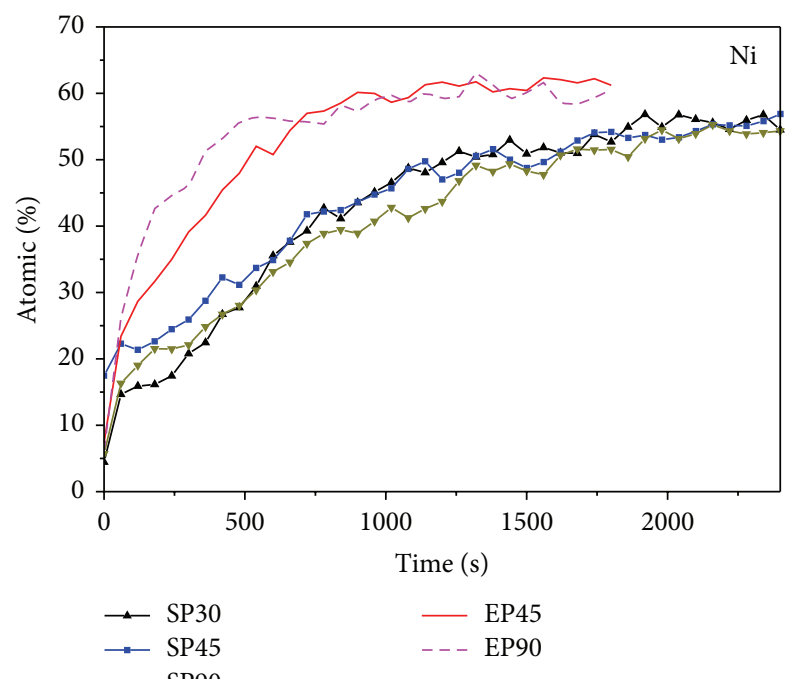

(a)

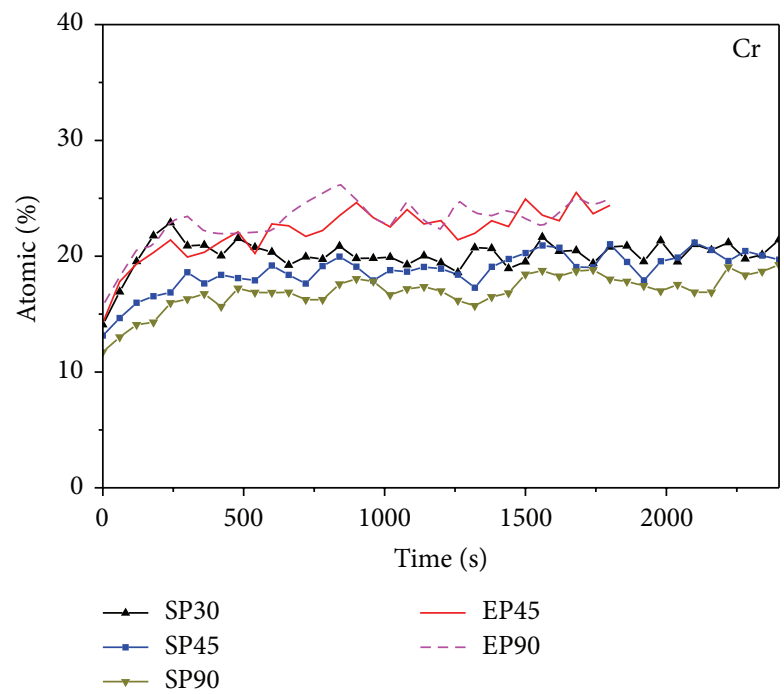

(c)

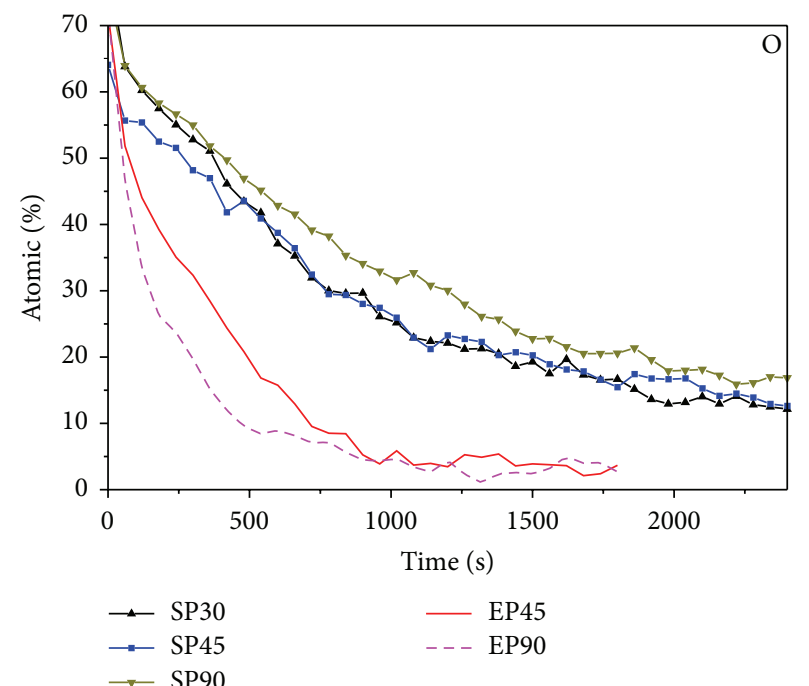

(b)

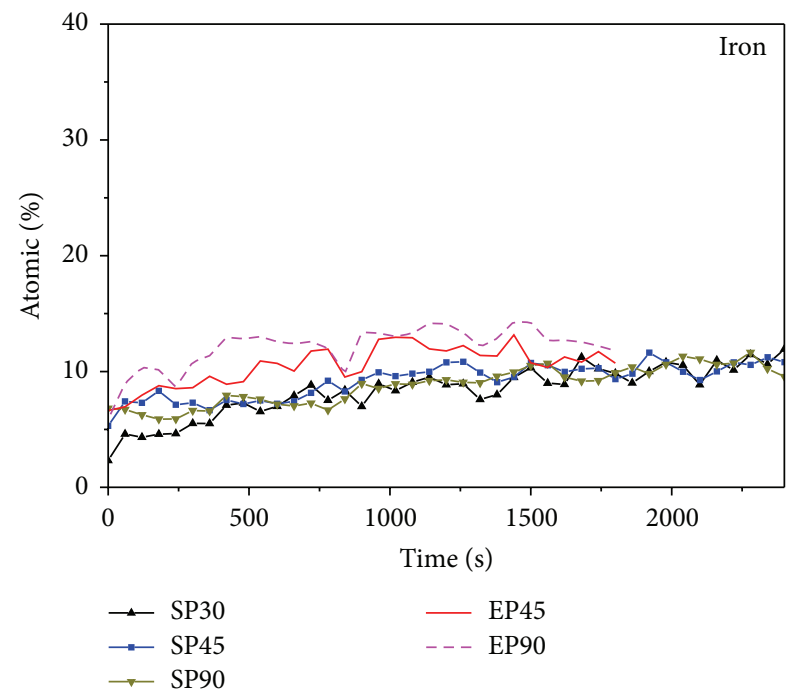

(d)

FIGURE 11: XPS depth profiles of the oxide layer for the elements (a) nickel, (b) oxygen, (c) chromium, and (d) iron.

mass-transfer property in the liquid phase that is governed by the solubility.

The corrosion-release rate can be controlled by the surface modification using electropolishing, as shown in Figure 9(b). The electropolishing treatment modifies the surface roughness and structure of the oxide layer. It is assumed that electropolishing reduces the density of dislocations which provide short-circuit paths for the diffusion of metal ions in the matrix [22] and promote the formation of a passive film in the primary coolant environment at high temperature. Figure 11 shows the XPS depth profiles for the individual elements Ni, O, Cr, and Fe in the oxide layer of Alloy 690. The content of nickel in the oxide layer of the specimens treated only by shot peening was more strongly reduced than in case of the electropolished specimens. The depletion of nickel in the oxide film is balanced by oxygen because the amount of chromium and iron did not change considerably, as shown in
Figures 11(c) and 11(d). The oxygen distribution in the oxide layer (Figure 11(b)) shows that the electropolishing treatment reduced the thickness of the oxide film and maintained a higher nickel content in comparison to the specimens treated only by shot peening. This result indicates that the additional electropolishing after shot peening could effectively mitigate the dissolution of nickel ions from SG tube materials.

\section{Conclusions}

The control of the nickel ion release rate is very important for reducing the radioactive dose rate and the deterioration of fuel performance in nuclear power plants. In this study, the surface residual stress of Alloy 690 was measured and its effect on the corrosion behavior was investigated. The modification of the SG tube surface induced by shot peening and electropolishing could affect the corrosion rate under primary 
water conditions. Compressive residual stress is induced by the shot peening treatment, and its value depends on the shot peening intensity at the surface of Alloy 690. Higher shot peening intensity causes reduction in the corrosion rate. It is considered that the compressive residual stress beneath the surface layer suppresses the metal-ion transfer in the alloy matrix. At low shot peening intensity, the corrosion rate is not remarkably changed but the oxide morphology of the corrosion products was changed from polyhedral shape to a needlelike type. When the surface was further modified by electropolishing after shot peening, the corrosion rate was reduced to almost a quarter of that obtained by shot peening only. The dissolution of nickel ions from SG tube materials was mitigated by the additional electropolishing treatment after the shot peening process.

\section{Conflict of Interests}

The authors declare that there is no conflict of interests regarding the publication of this paper.

\section{Acknowledgment}

This work was supported by the National Research Foundation of Korea (NRF) grant funded by the Korea government (MSIP).

\section{References}

[1] N. Engler, C. Brun, and M. Gullodo, Optimization of SG Tubes Prefilming Process to Reduce Nickel Release, NPC, Berlin, Germany, 2008.

[2] F. Carette, "Impact of the surface state of steam generator tubes on the release of corrosion products in pressurized water reactors," in Proceedings of the International Conference on Water Chemistry of Nuclear Reactor Systems, Jeju, Republic of Korea, 2006.

[3] Y. J. Kim, "Reactor core risk assessment on $\mathrm{Zn}$ injection in PWR," in Proceedings of the UNIST MNE Seminar, October 2014.

[4] K. Fruzzetti, "Pressurized water reactor primary water chemistry guidelines, Rev. 6," EPRI Report, 2007.

[5] C. J. Wood, "Water chemistry control in lwrs," Comprehensive Nuclear Materials, vol. 5, pp. 17-47, 2012.

[6] F. Giraudeau, D. H. Lister, D. R. Morris, U. Setthanan, F. R. Steward, and L. T. Yang, "Henry's law constant for hydrogen in high temperature water with dissolved lithium and boron," Canadian Journal of Chemical Engineering, vol. 86, no. 6, pp. 1032-1038, 2008.

[7] D. H. Lee, M. S. Choi, and U. C. Kim, The Effect of the Hydrogen and Li/B Concentration on the Stress Corrosion Cracking of Alloy 600 in Simulated PWR Primary Water at $330^{\circ} \mathrm{C}$, NPC, Jeju, Republic of Korea, 2006.

[8] D. S. Morton, S. A. Attanasio, and G. A. Young, Primary Water SCC Understanding and Characterization Through Fundamental Testing in the Vicinity of the Nickel/Nickel Oxide Phase Transition, NPC, Jeju, Republic of Korea, 2006.

[9] Z. Zhang, J. Wang, E.-H. Han, and W. Ke, "Effects of surface state and applied stress on stress corrosion cracking of Alloy
690TT in lead-containing caustic solution," Journal of Materials Science and Technology, vol. 28, no. 9, pp. 785-792, 2012.

[10] M. Clauzel, M. Guillodo, and M. Foucault, Correlation between Ni Base Alloys Surface Conditioning and Cation Release Mitigation in Primary Coolant, NPC, Québec, Canada, 2010.

[11] L. Guinard, O. Kerrec, D. Noel, S. Gardey, and F. Coulet, "Influence of the initial surface condition on the release of nickel alloys in the primary circuit of PWRs," Nuclear Energy, vol. 36, no. 1, pp. 19-27, 1997.

[12] F. Huang, J. Q. Wang, E. H. Han, and W. Ke, "Short-time oxidation of alloy 690 in high-temperature and high-pressure steam and water," Journal of Materials Science and Technology, vol. 28, no. 6, pp. 562-568, 2012.

[13] S. E. Ziemniak, M. Hanson, and P. C. Sander, "Electropolishing effects on corrosion behavior of 304 stainless steel in high temperature, hydrogenated water," Corrosion Science, vol. 50, no. 9, pp. 2465-2477, 2008.

[14] J. J. Kai, C. H. Tsai, and G. P. Yu, “The IGSCC, sensitization, and microstructure study of Alloys 600 and 690," Nuclear Engineering and Design, vol. 144, no. 3, pp. 449-457, 1993.

[15] P. Hernalsteen, "PWSCC in the tube expansion zone- an overview," Nuclear Engineering and Design, vol. 143, no. 2-3, pp. 131-142, 1993.

[16] V. N. Shah, D. B. Lowenstein, A. P. L. Turner et al., "Assessment of primary water stress corrosion cracking of PWR steam generator tubes," Nuclear Engineering and Design, vol. 134, no. 2-3, pp. 199-215, 1992.

[17] S. E. Ziemniak and M. Hanson, "Corrosion behavior of NiCrFe Alloy 600 in high temperature, hydrogenated water," Corrosion Science, vol. 48, no. 2, pp. 498-521, 2006.

[18] J. F. Ziegler and J. P. Biersack, SRIM-2000, 40: The Stopping and Range of Ions in Matter, IBM-Research, Yorktown, NY, USA, 2000.

[19] M. R. Fard, T. E. Blue, and D. W. Miller, "SiC semiconductor detector power monitors for space nuclear reactors," in Proceedings of the Space Technology and Applications International Forum (STAIF'04), Albuquerque, NM, USA, February 2004.

[20] A. Gill, A. Telang, S. R. Mannava et al., "Comparison of mechanisms of advanced mechanical surface treatments in nickel-based superalloy," Materials Science and Engineering A, vol. 576, pp. 346-355, 2013.

[21] M. J. Seo, H.-S. Shim, K. M. Kim, S.-I. Hong, and D. H. Hur, "Influence of surface roughness on the corrosion behavior of Alloy 690TT in PWR primary water," Nuclear Engineering and Design, vol. 280, pp. 62-68, 2014.

[22] N. Shaigan, W. Qu, D. G. Ivey, and W. Chen, "A review of recent progress in coatings, surface modifications and alloy developments for solid oxide fuel cell ferritic stainless steel interconnects," Journal of Power Sources, vol. 195, no. 6, pp. 15291542, 2010. 

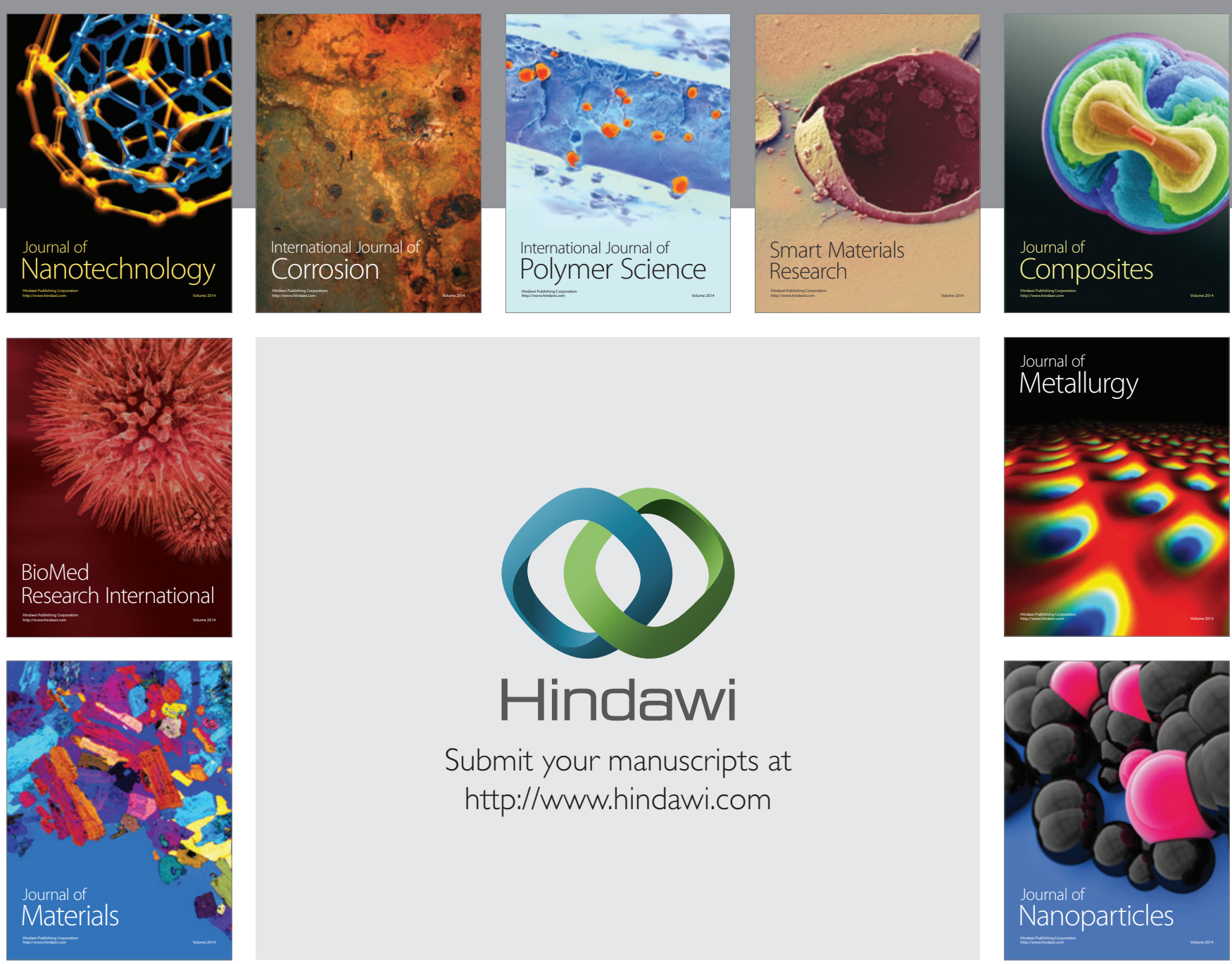

Submit your manuscripts at http://www.hindawi.com
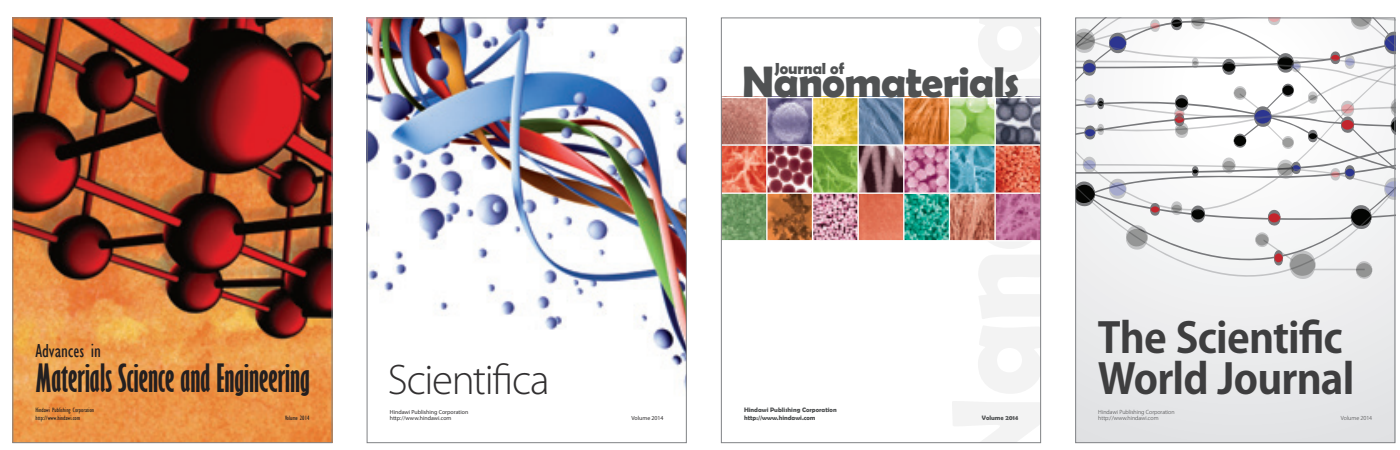

\section{The Scientific World Journal}
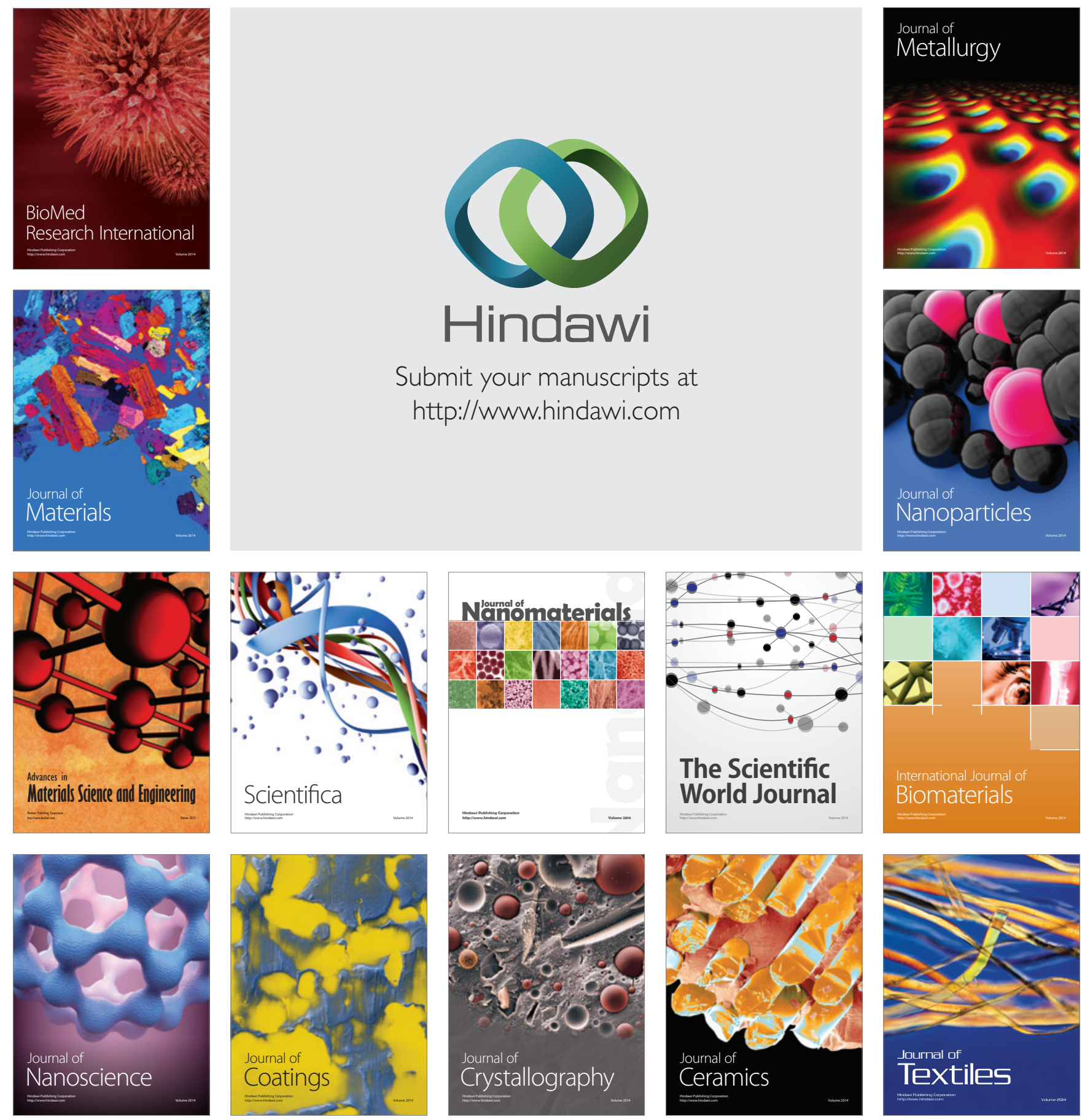